\title{
Measurement and Assessment of Occupational Exposure to Solar Ultraviolet Radiation in Makurdi Metropolis, Benue State, Central Nigeria
}

\author{
Terver Sombo*, Terkimbi Jude Shivil, Tertsea Igbawua \\ Department of Physics, Federal University of Agriculture, Makurdi, Nigeria \\ Email address: \\ jtsombo@gmail.com (T. Sombo) \\ ${ }^{*}$ Corresponding author

\section{To cite this article:} \\ Terver Sombo, Terkimbi Jude Shivil, Tertsea Igbawua. Measurement and Assessment of Occupational Exposure to Solar Ultraviolet \\ Radiation in Makurdi Metropolis, Benue State, Central Nigeria. Radiation Science and Technology. Vol. 7, No. 2, 2021 , pp. 32-40. \\ doi: $10.11648 /$ j.rst.20210702.13
}

Received: April 6, 2021; Accepted: May 3, 2021; Published: May 26, 2021

\begin{abstract}
This work measured and modeled Ultraviolet (UV) Radiation exposure of outdoor workers (Traders, Drivers/Commuters and Construction workers) within Makurdi Metropolis. Digital broad band meter was used to measure Irradiance across the three occupations under consideration. Polymer Polysolphone dosimeters were used to quantify the amount of solar UVR absorbed by workers of these occupations, UV/VIS-Spectrophotometer was used to measure both post and pre-absorbance while GPS was used to measure the coordinate of the Sampling sites. The Polymer Polysulphone dosimeters were fitted on vital solar radiation access areas on a plastic human shape and placed in the sun from 9:30am4:00pm (6 hours 30 minutes). The result shows that head top had the highest values of $8.73 \mathrm{~kJ} / \mathrm{m}^{2}, 6.67 \mathrm{~kJ} / \mathrm{m}^{2}$ and $7.40 \mathrm{~kJ} / \mathrm{m}^{2}$ for drivers/commuters, construction workers and traders respectively while the dosimeters worn under clothe cover had the least values of $2.06 \mathrm{~kJ} / \mathrm{m}^{2}, 2.56 \mathrm{~kJ} / \mathrm{m}^{2}, 3.07 \mathrm{~kJ} / \mathrm{m}^{2}$ at the market square, car park and construction site respectively. Similarly, UV Irradiances at various intervals were measured and the cumulative exposures calculated to be $610.98 \mathrm{~kJ} / \mathrm{m}^{2}, 1923.84 \mathrm{~kJ} / \mathrm{m}^{2}$ and $3526.92 \mathrm{~kJ} / \mathrm{m}^{2}$ respectively. The work sets a reliable baseline data for solar UV radiation monitoring in Makurdi Benue State, Nigeria.
\end{abstract}

Keywords: Solar Ultraviolet Radiation, Occupational Exposure, Irradiance, Absorbance, Cumulative Exposure

\section{Introduction}

Outdoor work environments have high exposure levels of UV radiation and exposure is habitual during the noon hours [1] especially in regions with high solar radiation like Nigeria. Specifically, both environmental and individual factors affect acute and long-term (cumulative) solar UV radiation exposure levels of outdoor workers in Nigeria. For instance, the work environment may involve the presence of reflective surfaces, such as water for maritime workers or glass and metal for construction workers. More so, both governmental and non-governmental organizations expect workers to carry out their daily duties during the mid-hours of the day and/or during the warm seasons, as this is always the case with the agricultural and construction jobs. Also, working posture is very important in determining the areas on the surface of the body that show with the high exposures, such as in agriculture and construction, where different working tasks are involved. For example, tasks which involve fruit harvesting from the tree or the ground, the activity of a mason using bricks in open construction sites, or a tiller in open agricultural fields may respectively induce a high exposure of the face, chest, back or the nape. Behaviors that can reduce over-exposure to UV radiation during our leisure time include wearing of protective clothing, caps, sun glasses, and application of sunscreen $[2,3]$. These items play a vital role in determining the skin and eye exposure of a worker in the environment.

The dark pigmentation in the native Africans shields against the effects of UV in damaging the skin surface, while per-mitting 
sufficient UV penetration to the epidermis to produce sufficient amounts of vitamin D [3]. Solar UV radiation is responsible for the production and synthesis of vitamin $\mathrm{D}$ but over-exposure to it causes sunburn, skin cancer, skin deformation, eye problems (such as cataracts, pterygium), and immune depression [3-5]. Human exposure to solar ultraviolet radiation has important public health implications. According to Engelsen (2010) [6], there exist In vitro models and documented experiments describing photo conversion of pro-vitamin D to pre-vitamin D [7].

The UV radiation represents a small portion of the solar radiation spectrum (SRS) that, spanned through the wavelength of $\sim 100 \mathrm{~nm}$ to $\sim 400 \mathrm{~nm}[8,9]$. UV radiation comprises of three main components namely UV-A (ranges from $315-400 \mathrm{~nm}$ ), UV-B (ranges from $280-315 \mathrm{~nm}$ ) and UV-C (ranges from $100-280 \mathrm{~nm}$ ) [9]. UV-A rays have the longest wavelengths, followed by UV-B, and UV-C rays which have the shortest wavelengths and are more dangerous than UV-A and B $[9,10]$. Whereas UV-A and UV-B rays can are transmitted through the atmosphere, all UV-C and some UV-B rays are attenuated by the Earth's ozone layer [11]. The wavelengths of UV radiation for the production of vitamin D fall essentially in the UV-B and part of the short UV-A bands (shorter than $330 \mathrm{~nm}$ )[11].

The aim of this study is to measure and model occupational exposure to solar UV radiation in Makurdi Metropolis. The work involves calibration of Polymer dosimeters for UV exposure measurements and measurement of UV occupational exposures using plastic human dummies in different work places. Outdoor workers are often engaged in one or more risky behaviors such as going out bare chested, wearing short-sleeve or sleeveless shirts, and limited face, eye, and neck protection. If unprotected (which is usually observed), workers could suffer both short and long term health effects such as erythema (reddening of the skin), peeling and blistering of the skin, photosensitivity, immune system defects, skin cancer, and eye problems.

\section{Materials and Method}

\subsection{Study Site}

The study is Makurdi town which is sited between latitude $7^{\circ} 38^{\prime} \mathrm{N}-7^{\circ} 50^{\prime} \mathrm{N}$, and longitude $8^{\circ} 24^{\prime} \mathrm{E}$ and $8^{\circ} 38^{\prime} \mathrm{E}$. It is situated in the Benue valley in the North Central region of Nigeria. River Benue which is the second largest river in the country cuts across Makurdi town and divides it into the north and south banks. Fishing activities in the river are responsible for the high consumption of fish and other sea foods in the study area. The main occupation of the inhabitants of Makurdi town is made up largely of people who engage in civil service duties, commercial activities and agrarian peasantry. Makurdi town is the headquarters of Makurdi Local Government Area and capital of Benue State.

\subsection{Materials}

The following materials were used in this research; i. A digital UV broadband meter

ii. Twelve-channel GPS

iii. Polymer polysulphone dosimeters $(2 \mathrm{~cm}$ by $2 \mathrm{~cm})$ and iv. UV/Vis spectrophotometer.

\subsection{Procedure}

i. A digital UV broadband meter, the Educator (No. P36510) was used for measuring UV exposures. The UV meter detects both UV-A and UV-B and then calculates the UV index and UV irradiance (solar power density in $\mathrm{W} / \mathrm{m}^{2}$ ) through averaging the readings of the various wavelengths according to the Erythemal Action Spectrum [5].

ii. The longitude, latitude and altitude of the measurement sites were measured by a twelve-channel GPS (etrex by Garmin Ltd, USA).

iii. Some pieces of polymer polysulphone dosimeter $(2 \mathrm{~cm}$ by $2 \mathrm{~cm}$ ) were used in this work. Some were used for calibration and others were attached on different parts of a human manikin and positioned at various locations representing occupations.

iv. UV/Vis spectrophotometer, (UV-Vis serial no. 6305, designed by Jenway Co. Ltd, UK) were used in measuring the change in dosimeter absorbance.

\subsection{Dosimeter Calibration and Experimental Model}

The calibration of the dosimeters was done at the measurement site. This was achieved by subjecting 6 dosimeters each at Modern Market (traders), North bank motor park (Motorist/Passengers) and NUJ construction site (Construction workers) to series of solar UV radiation on a horizontal plane, while measuring the solar UV exposures with the UV meter. This was done to enable the dosimeters quantify UV exposures in $\mathrm{J} / \mathrm{m}^{2}$.

The desired quantities were calculated using;

$$
\begin{gathered}
\text { Exposure Quantity }\left(\mathrm{J} / \mathrm{m}^{2}\right)= \\
\text { Calibration factor (constant) } * \text { Absorbance (1) }
\end{gathered}
$$

The calibration factor is often considered as the gradient of a line and this was sufficiently approximated for a UV polysulphone dosimeter $[4,12,13]$.

The UV exposure (E) of each individual dosimeter was calculated using equation;

$$
E=\sum_{t_{1}}^{t_{2}} I * \Delta t
$$

Where $\mathrm{E}$ is the exposure in $\left(\mathrm{J} / \mathrm{m}^{2}\right)$, I is the measured irradiance $\left(\mathrm{W} / \mathrm{m}^{2}\right)$ and $\Delta \mathrm{t}$ is the exposure time interval from $\mathrm{t}_{1}$ to $\mathrm{t}_{2}[5]$.

\subsection{UV Exposure Measurements/Data Collection}

A calibration and exposure measurements of various occupations (Construction workers, drivers/Motorist, and traders) were done for each occupation per day at the same site and on the same day so as to avoid errors as a result of mismatch in UV radiation measurements when measured on different days. In this work, different dosimeters of size $2 \mathrm{~cm}$ 
$\mathrm{x} 2 \mathrm{~cm}$ were attached to different part of human plastic figure and exposure in UV radiation during the working hours per day. The pre-exposure optical absorbance and post-exposure optical absorbance were also estimated and the change in optical absorbance was computed for each exposed dosimeter.

\section{Result}

Tables 1, 2, and 3 show the results for cumulative exposure of the dosimeters at different sites during calibration. During calibration, the time interval used for Construction site, modern market and north bank car park was 60, 10 and 30 minutes respectively. Equation (2) was used in calculating UV exposure of each dosimeter at the various time intervals. The total exposure for each dosimeter was the cumulative sum of the exposure calculated for the current exposure intervals of (60, 10 and 30 minutes) and the sum of previous exposures of the dosimeters considered in that order. The UV exposure of each dosimeter was estimated from a single measurement made at the end of an interval of 60,10 and 30 minutes respectively. This means calibration time for construction site, modern market and north bank car park lasted for 6, 1 and 3 hours respectively. The UV irradiance was therefore approximated to be constant [4] for the 60,10 and 30-minute exposure intervals. Results showed that the change in optical absorbance increased with increase in exposure time for all the construction sites.

The cumulative exposures at the end of the calibration time for construction site, modern market and north bank car park were $3526.92,610.98$ and $1923.84 \mathrm{~kJ} / \mathrm{m}^{2}$ respectively. Figures 1 and 2 shows dosimeter calibration and response curves for construction occupational exposure site. Figures 3 and 4 shows dosimeter calibration and response curves for modern market occupational exposure site and Figures 5 and 6 shows dosimeter calibration and response curves for north bank car park occupational exposure site. Also, figure 7 shows cumulative Exposure $\left(\mathrm{kJ} / \mathrm{m}^{2}\right)$ of dosimeters placed on strategic positions at various exposure sites from 10 am to $4.30 \mathrm{pm}$ covering a 6.5 hour period. Results shows that dosimeters placed on the head recorded highest cumulative UV exposures of $6.67,7.40$ and $8.73 \mathrm{kJm}^{2}$ for construction workers, traders and commuters in the park respectively. The lowest readings were obtained for dosimeters placed under the cloth with reading of $3.07,2.06$ and $2.56 \mathrm{kJm}^{2}$ for construction workers, traders and commuters in the park respectively.

Table 1. Cumulative UV Exposure of at Construction Sites.

\begin{tabular}{|c|c|c|c|c|c|}
\hline S/No & $\begin{array}{l}\text { Dosimeter Exposure } \\
\text { Time (Mins) }\end{array}$ & $\begin{array}{l}\text { Change in Optical } \\
\text { Absorbance }\left(\Delta \mathbf{A}_{330}\right)\end{array}$ & $\begin{array}{l}\text { UV Irradiance for } \\
\text { Exposure Interval }\left(\mathrm{W} / \mathrm{m}^{2}\right)\end{array}$ & $\begin{array}{l}\text { Approx. UV Exposure for } \\
\text { each Interval }\left(\mathrm{kJ} / \mathrm{m}^{2}\right)\end{array}$ & $\begin{array}{l}\text { Cumulative UV } \\
\text { Exposure }\left(J / \mathbf{m}^{2}\right)\end{array}$ \\
\hline 1 & 60 & 0.288 & 115.5 & 415.8 & 415.80 \\
\hline 2 & 120 & 0.373 & 117.3 & 422.28 & 838.08 \\
\hline 3 & 180 & 0.430 & 189.6 & 682.56 & 1520.64 \\
\hline 4 & 240 & 0.578 & 227.3 & 818.28 & 2338.92 \\
\hline 5 & 300 & 0.605 & 175.4 & 631.44 & 2970.36 \\
\hline 6 & 360 & 0.633 & 154.6 & 556.56 & 3526.92 \\
\hline
\end{tabular}

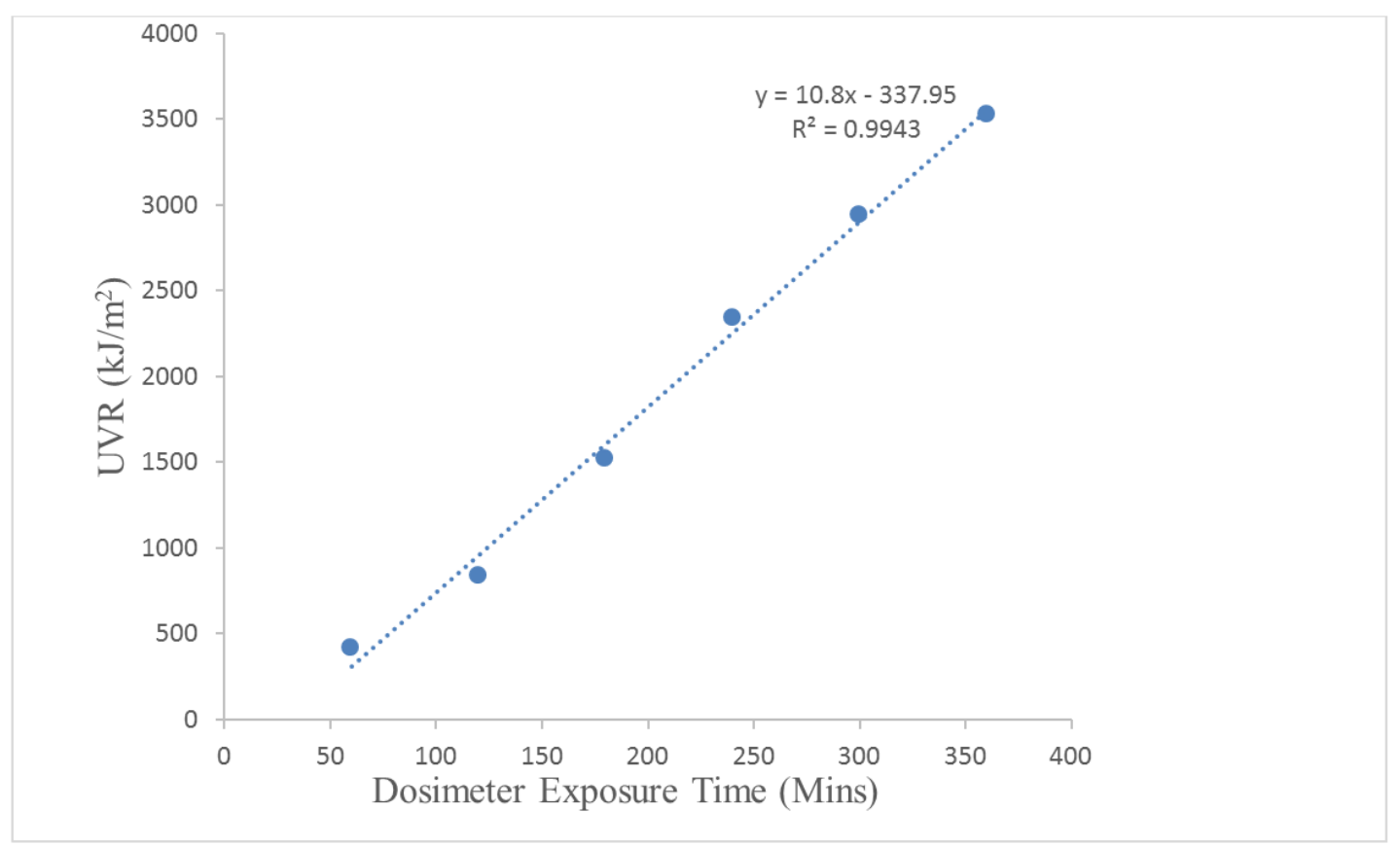

Figure 1. Dosimeter Calibration Curve at Construction Site. 


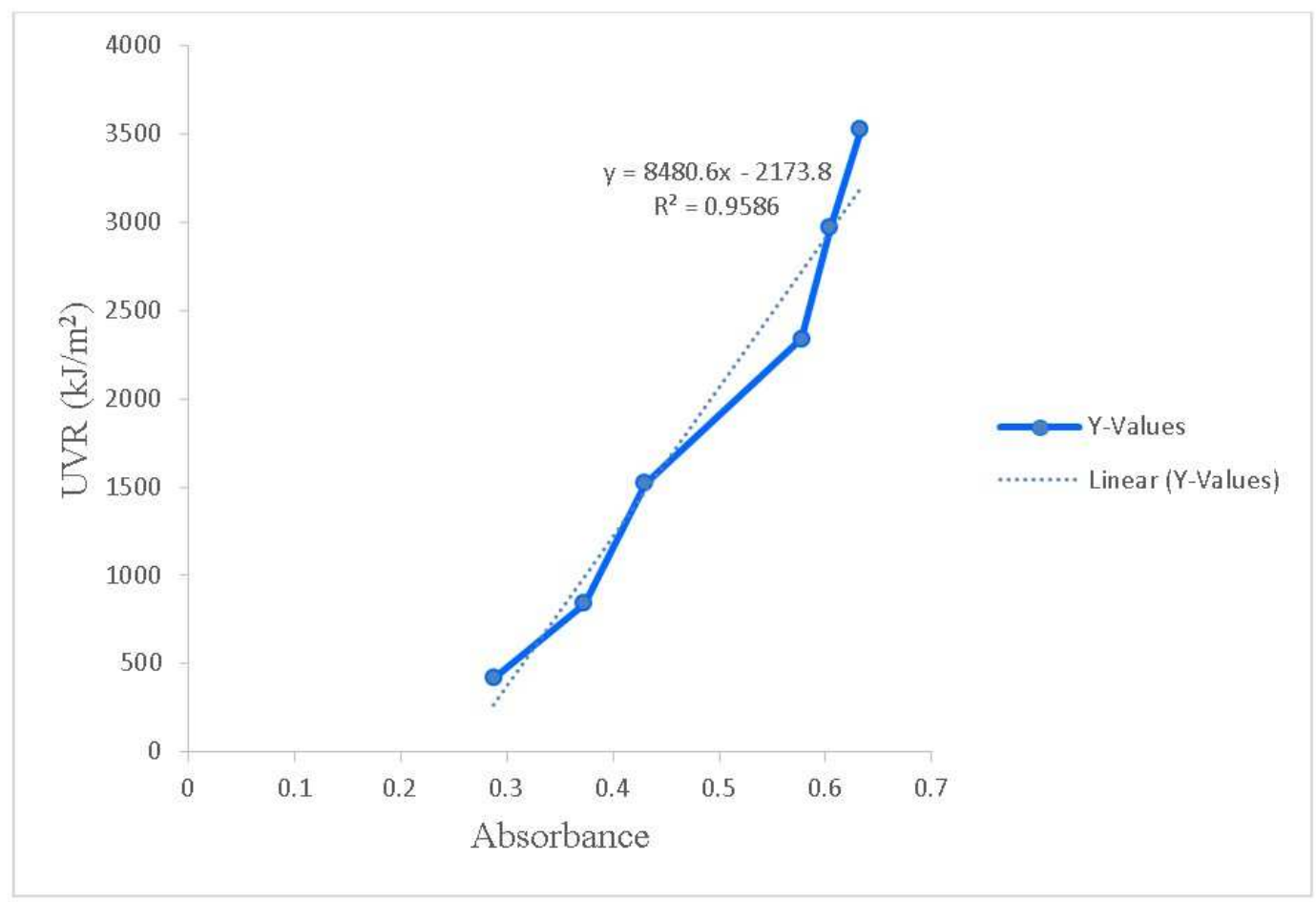

Figure 2. Polymer Polysulphone Dosimeter Response Curve at Construction Site.

Table 2. Cumulative UV at Modern Market.

\begin{tabular}{llllll}
\hline \multirow{2}{\text{S/No}}{} & $\begin{array}{l}\text { Dosimeter Exposure } \\
\text { Time (Mins) }\end{array}$ & $\begin{array}{l}\text { Cumulative UV } \\
\text { Exposure }\left(\mathbf{k J} / \mathbf{m}^{2}\right)\end{array}$ & $\begin{array}{l}\text { Change in Optical } \\
\text { Absorbance }\left(\Delta \mathbf{A}_{\mathbf{3 3 0}}\right)\end{array}$ & $\begin{array}{l}\text { UV Irradiance for } \\
\text { Exposure Interval }\left(\mathbf{W} / \mathbf{m}^{2}\right)\end{array}$ & $\begin{array}{l}\text { Approx. UV Exposure for } \\
\text { each Interval }\left(\mathbf{k J} / \mathbf{m}^{2}\right)\end{array}$ \\
\hline 1 & 10 & 91.68 & 0.115 & 152.8 & 91.68 \\
2 & 20 & 179.16 & 0.202 & 145.8 & 87.48 \\
3 & 30 & 290.4 & 0.245 & 198.73 & 119.24 \\
4 & 40 & 401.82 & 0.281 & 185.7 & 111.42 \\
5 & 50 & 518.04 & 0.328 & 193.7 & 116.22 \\
6 & 60 & 610.98 & 0.382 & 154.9 & 92.94 \\
\hline
\end{tabular}

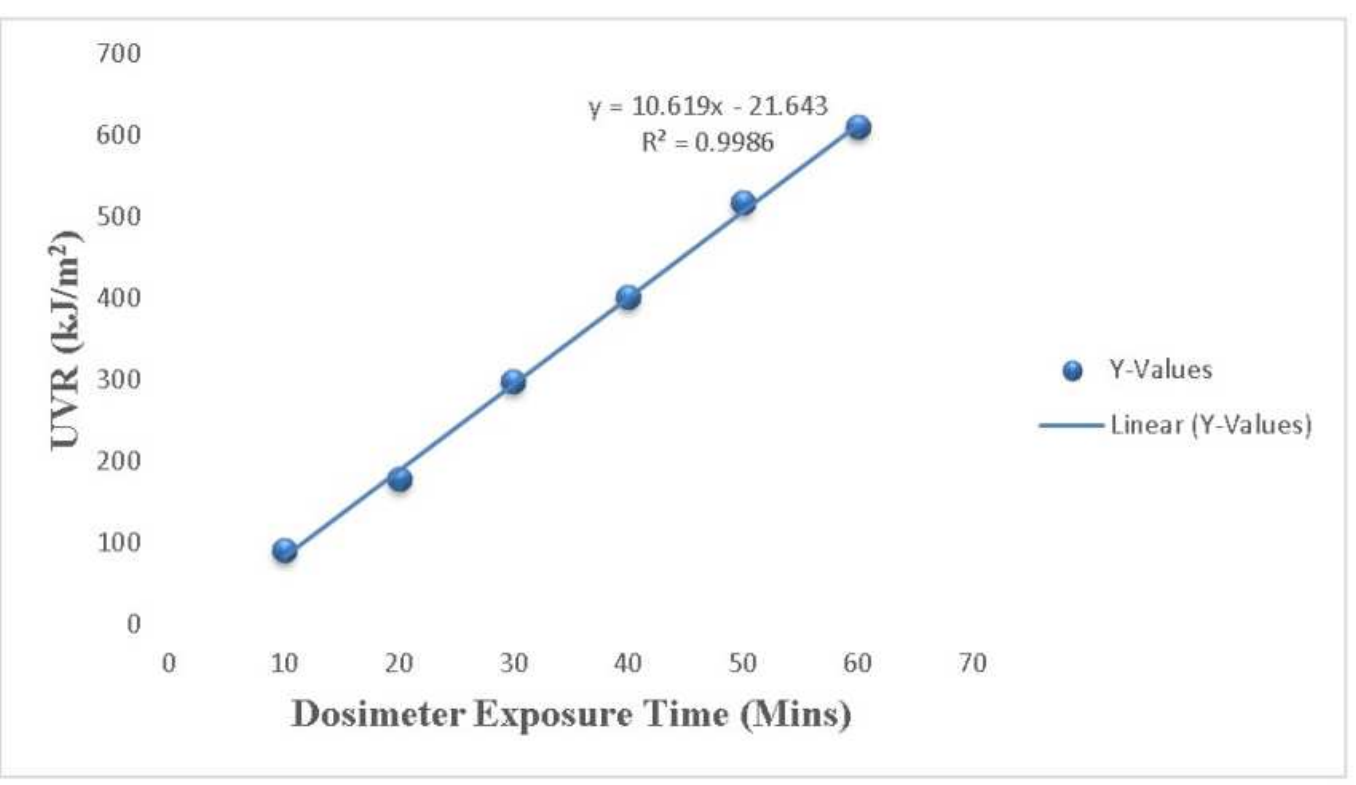

Figure 3. Dosimeter Calibration Curve at Modern Market. 


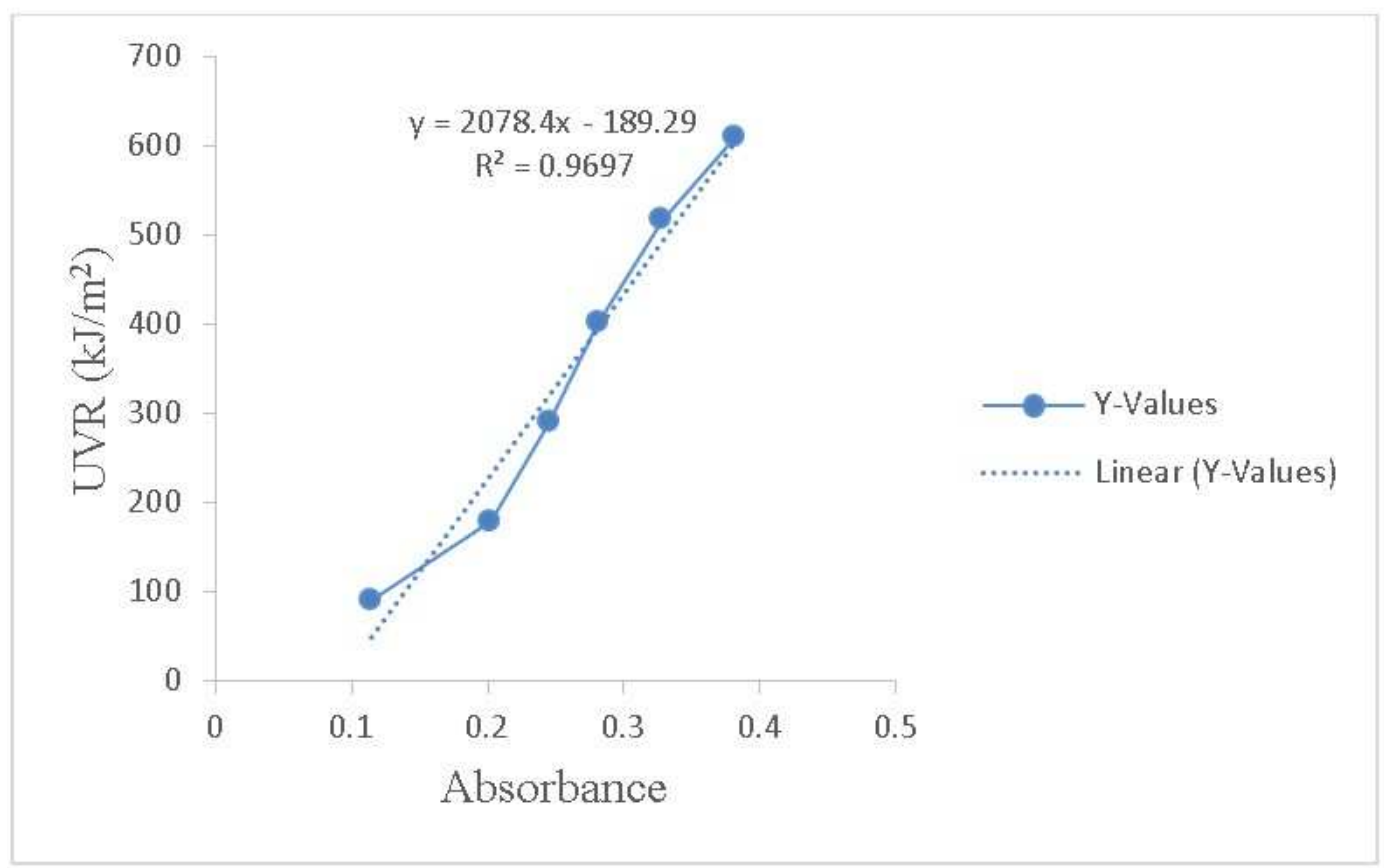

Figure 4. Polymer Polysulphone Dosimeter Response Curve at Modern Market.

Table 3. Cumulative UV Exposure at the North Bank Car Park.

\begin{tabular}{llllll}
\hline \multirow{2}{*}{ S/No } & $\begin{array}{l}\text { Dosimeter Exposure } \\
\text { Time (Mins) }\end{array}$ & $\begin{array}{l}\text { Change in Optical } \\
\text { Absorbance }\left(\boldsymbol{\Delta A}_{\mathbf{3 3 0}}\right)\end{array}$ & $\begin{array}{l}\text { UV Irradiance for } \\
\text { Exposure Interval }\left(\mathbf{W} / \mathbf{m}^{2}\right)\end{array}$ & $\begin{array}{l}\text { Approx. UV Exposure for } \\
\text { Each Interval }\left(\mathbf{k J} / \mathbf{m}^{2}\right)\end{array}$ & $\begin{array}{l}\text { Cumulative UV } \\
\text { Exposure }\left(\mathbf{k J} / \mathbf{m}^{2}\right)\end{array}$ \\
\hline 1 & 30 & 0.199 & 127.7 & 229.86 & 229.86 \\
2 & 60 & 0.227 & 177.8 & 320.04 & 549.90 \\
3 & 90 & 0.391 & 183.2 & 329.76 & 879.66 \\
4 & 120 & 0.460 & 196.0 & 352.80 & 1232.46 \\
5 & 150 & 0.487 & 205.5 & 369.90 & 1602.36 \\
6 & 180 & 0.510 & 178.6 & 321.48 & 1923.84 \\
\hline
\end{tabular}

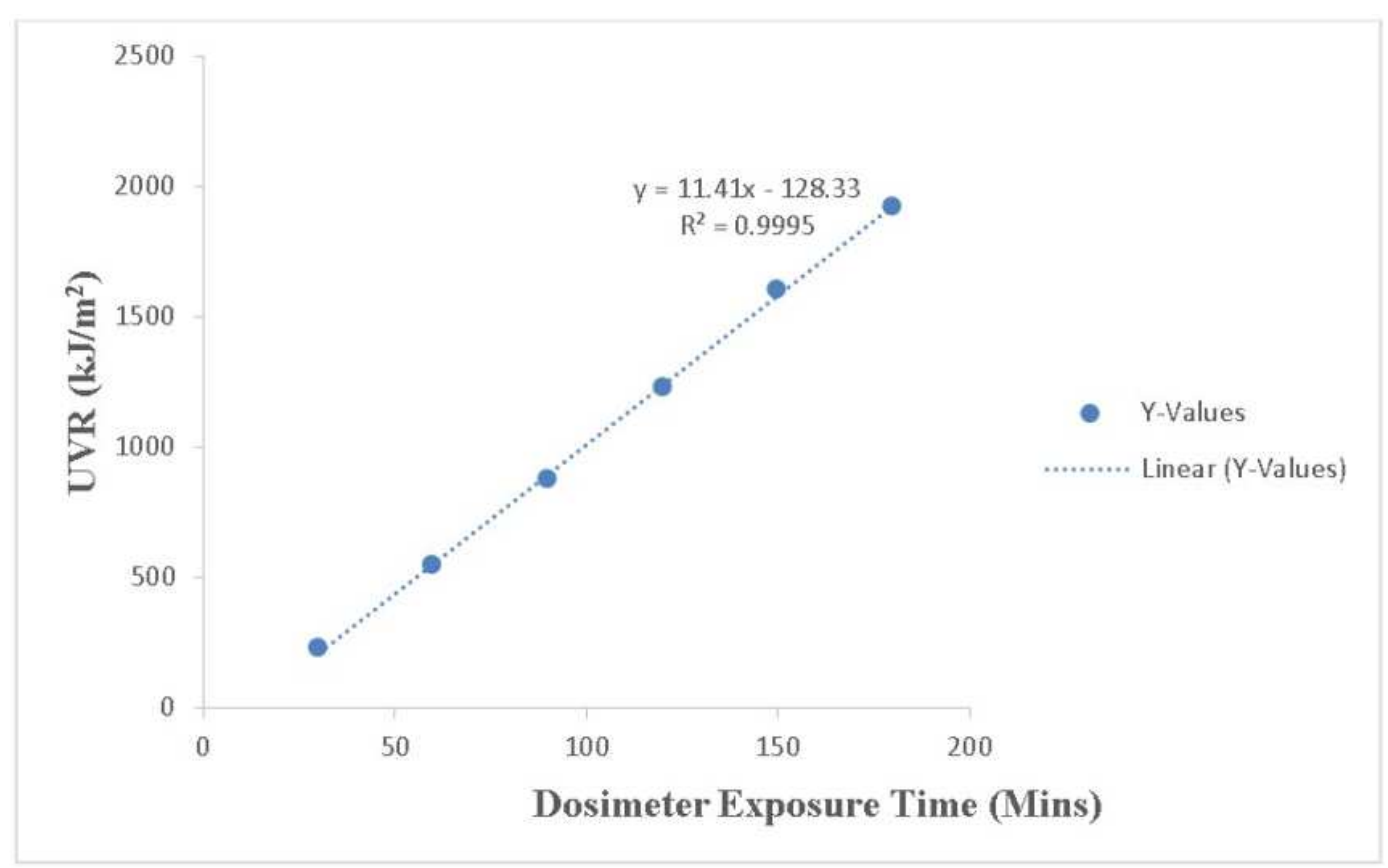

Figure 5. Dosimeter Calibration Curve at the North Bank Car Park. 


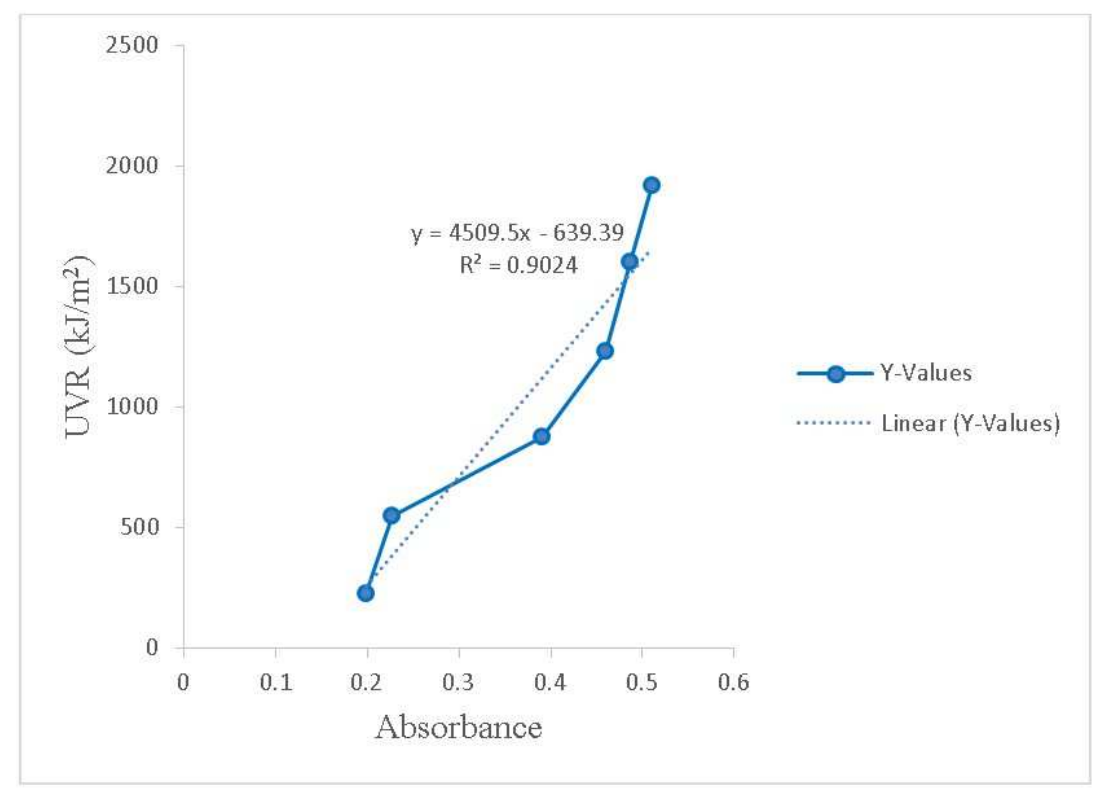

Figure 6. Polymer Polysulphone Dosimeter Response Curve at the North Bank Car Park.

Table 4. Cumulative Exposure $\left(\mathrm{kJ} / \mathrm{m}^{2}\right)$ of Dosimeters Placed on Various Body Parts at Different Sampling Sites.

\begin{tabular}{|c|c|c|c|c|}
\hline \multirow{2}{*}{ S/No. } & \multirow{2}{*}{ Body parts } & \multicolumn{3}{|c|}{ Various Occupations Research } \\
\hline & & Traders & Construction workers & Car Park \\
\hline 1 & Head & 7.40 & 6.67 & 8.73 \\
\hline 2 & RT Eye & 3.96 & 3.50 & 3.72 \\
\hline 3 & LT Eye & 3.10 & 3.26 & 3.24 \\
\hline 4 & RT Hand & 5.68 & 5.80 & 6.13 \\
\hline 5 & LT Hand & 4.01 & 5.07 & 5.50 \\
\hline 6 & Chest & 5.54 & 6.58 & - \\
\hline 7 & Clothed & 2.06 & 3.07 & 2.56 \\
\hline
\end{tabular}

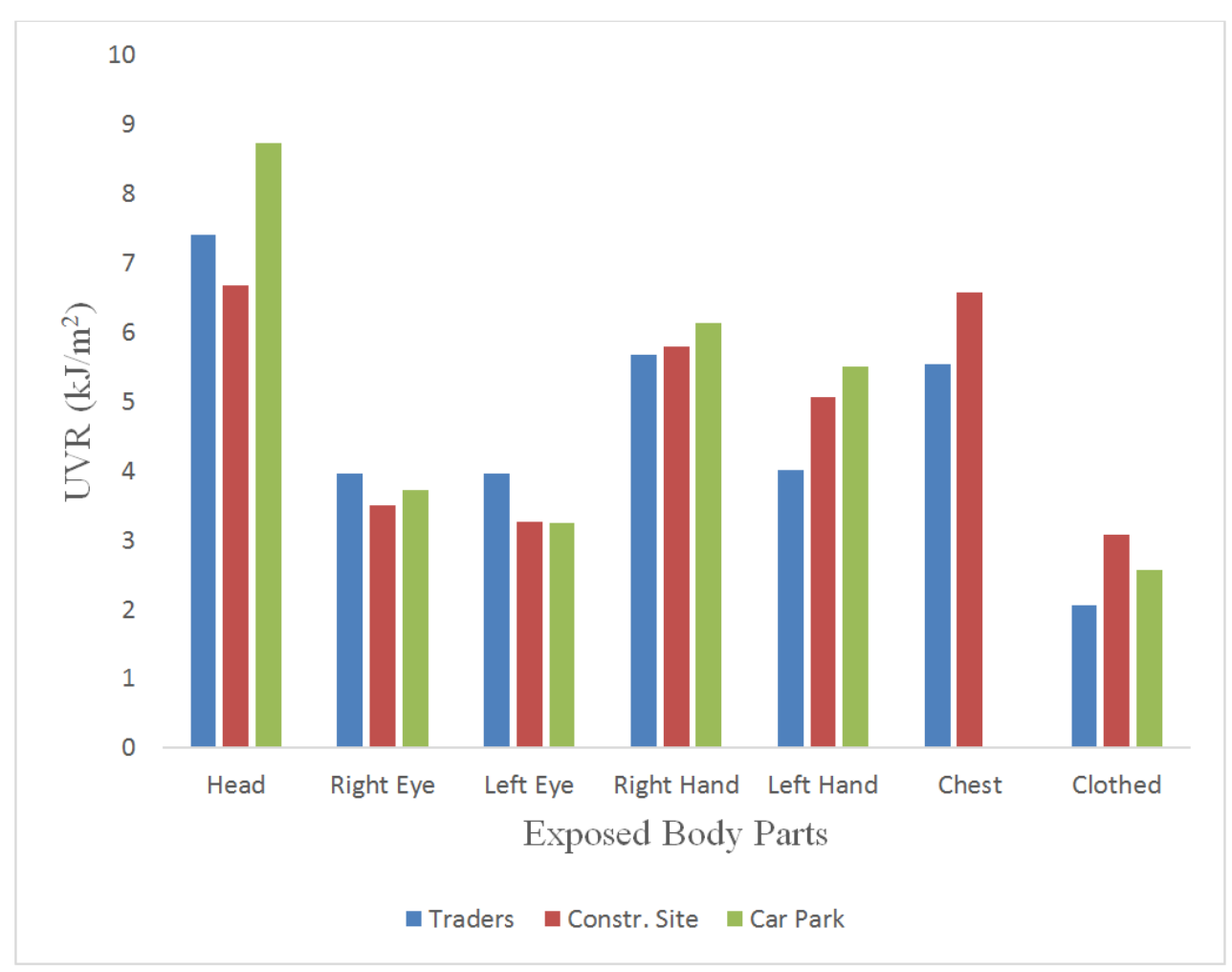

Figure 7. Cumulative Exposure of Dosimeters placed on various body parts. 


\section{Discussion}

This work presents UV exposure measurement at different occupational exposure sites which covers construction workers, traders and commuters in open environment using polymer polysulphone dosimeters. The calibration equations were successfully obtained covering the various exposure sites. For construction site, the modern market and car park, the calibration equations are given by

$$
\begin{aligned}
& y=8480.6 x\left(R^{2}=0.9586\right), \\
& y=2078.4 x\left(R^{2}=0.9697\right) \\
& y=4509.5 x\left(R^{2}=0.9024\right)
\end{aligned}
$$

respectively to make the dosimeter effectively estimate cumulative UV radiation exposures in $\mathrm{J} / \mathrm{m}^{2}$. The slope of the calibration equation gives the calibration constant while $R^{2}$ shows the goodness of the calibration fit. From our results, it shows that all the polymer polysulphone dosimeters responded well to the changes in UV radiation exposure and hence used as tool for UV exposure measurements in the study area.

The occupational erythema UV exposure doses received by different parts of the body were assessed in the various exposure sites. The measurements were performed for individuals standing or walking upright in sunlight. The exposure dosimeters were placed on the head, right and left eyes, right and left hands, chest and underneath the cloth. The measurements were performed during clear sky conditions during the peak hours of solar radiation. Results show that there was a clear dependence of UV exposure on body geometry. For all the exposure sites, dosimeters placed on the head recorder high cumulative UV exposure doses, followed by the ones placed on the hands then the eyes. The values are $6.67,7.40$ and $8.73 \mathrm{kJm}^{2}$ for construction workers, traders and commuters in the park respectively. The values for dosimeters placed on right (left) eye was $3.96(3.10), 3.50(3.26)$ and $3.72(3.24) \mathrm{kJm}^{2}$ for construction workers, traders and commuters in the park respectively while the values for dosimeters placed on right (left) hand was 5.68 (4.01), 5.80 (5.07) and 6.13 (5.50) $\mathrm{kJm}^{2}$ for construction workers, traders and commuters in the park respectively. The variation in the exposure readings from different could be as a result of the fact that the sun movement was not directly overhead as well as having different intensities for the different days used in carrying out the measurements. The dosimeter placed inside the cloth recorded the least cumulative UV radiation across all location with values ranging from 2.06, 3.07 and 2.56 $\mathrm{kJ} / \mathrm{m}^{2}$ for traders at market square, construction workers at construction site and motorist/passengers at North bank motor park suggesting that the fabrics we put on assists in reducing direct UV radiation exposures to the skin thereby reducing the harm to our bodies.

The mean UV radiation exposures estimated for construction site, car park and market square were determined to be $4.850 \mathrm{~kJ} / \mathrm{m}^{2}, \quad 4.980 \mathrm{~kJ} / \mathrm{m}^{2}$ and $4.536 \mathrm{~kJ} / \mathrm{m}^{2}$ respectively for a 6.5 hour-exposure period. These values are higher than the recommended value by International Commission on Non-Ionizing Radiation Protection (ICNIRP) guidelines for human occupational exposure limit of $30 \mathrm{~J} / \mathrm{m}^{2}$ (effective) to the eye and skin when spectral irradiance is weighted against the hazard spectrum from 180 to $400 \mathrm{~nm}$ (ICNIRP) [14]. Also, the recommendation by the International Electrochemical Commission (1995) is that the annual UV exposure doses should exceed an erythema weighted dose of $15 \mathrm{~kJ} / \mathrm{m}^{2}$ equivalent to 150 Standard Erythema Dose (SED). The measurements reported in this work are higher that the permissible limits, therefore capable of causing skin and eye related problems. Basically, majority of the damage due to unprotected exposures result from chronic effects. According to Igbawua et al. [4], chronic UV exposures may result into accelerated skin aging process, increased the risk of developing skin cancers and eye related problems.

Daily cumulative UV exposures for construction site, modern market and north bank car park were 3526.92, 610.98 and $1923.84 \mathrm{~kJ} / \mathrm{m}^{2}$ respectively. The results from this study clearly show that, individuals who expose themselves without adequate protection are at high risk of developing chronic effects of UVR exposure even without the acute effects especially at the commuter motor parks. Although there maybe variation in the life style of different individuals due to the way the walk, sit or stand in sunlight. Apart from individuals that normally wear face caps, hats, or hair cover on their heads, majority of individuals normally leave their heads unprotected. The research has proven the necessity of always using UV protective clothing and eye cover among others as protection against high UV exposures which could lead to skin or eye damage.

In comparison to other studies, Sabburg et al. [15] aimed to determine the effect of cloud coverage on UVA exposures to humans in Toowoomba, Australia using broad-band visible-infrared and UVA sensors together with a sun tracking, wide-angle video camera. One day was recorded as $48 \%$ overall sky cloud coverage with the sun covered $60 \%$ and resulted in the daily UVA exposure of $688.8 \mathrm{~kJ} \mathrm{~m}^{-2}$. Two other days were recorded as $27 \%$ overall sky cloud coverage with the sun covered $40 \%$ and $100 \%$ resulting in daily UVA exposures of 652.5 and $568.1 \mathrm{~kJ} \mathrm{~m}^{-2}$ respectively. The results from this research shows that Makurdi have higher solar intensity than Toowoomba implying that individuals around this region are at higher risk of UVR effects especially those indulging in risky act such as those going about their duties without body cover especially, the constructions workers who are mostly found performing this act.

Also, a research done by Igbawua et al. [4], in Gboko, Central Nigerian used polysulphone dosimeters to measure UV exposures on different parts of an anatomical body and results showed that the dosimeter on the head reported the highest cumulative UV radiation exposure of $595.386 \mathrm{~J} / \mathrm{m}^{2}$ while the one placed in the pocket recorded the least 
cumulative UV exposure of $2.723 \mathrm{~J} / \mathrm{m}^{2}$ which indicates that Makurdi has high UV exposures than Gboko based on the reported results. Even though these two cities are located in the same state and country, the high variation in results is expected because the solar radiation measured in two separate days or season cannot be exactly the same since solar radiation is highly variable in time and space.

Many other studies focused more on solar UVR dose of certain body parts versus doses obtained in general directions. Thieden et al.[16] used a UV-sensitive spore-film system as a UV personal dosimeter to measure UV exposure on various parts of the body including the head, shoulder, upper arm, chest, and wrist. The study was performed at Bellevue, a public beach close to Copenhagen in Denmark. Results indicate that the head received the highest mean UV exposure of 19.7 SED whereas the chest received the lowest mean exposure of 6.6 SED.

Herlih yet al. [17] measured solar UV for recreational activities such as tennis, sailing, swimming, walking, golf, and gardening. People from each activity wore polysulphone badges on parts of the body such as the cheek, hand, shoulder, back, chest, thigh, and calf. The study took place in Hobart, Tasmania in February (summer) of 1991. Results indicate that collectively, those who sailed received the highest UV exposures $\left(1712 \mathrm{~J} / \mathrm{m}^{2}\right)$. In addition, taking all of the activities into consideration, the shoulder received the highest exposure of 0.43 . This result yet again proof that the Benue region receive higher UVR.

\section{Conclusion}

This research work made use of a chemical dosimeters fitted on a human like structure (manikin) to measure UV radiation on different body parts. The UV radiation exposure on different human body parts varies with difference in body geometry. From the result, the head top had the highest values of $8.73 \mathrm{~kJ} / \mathrm{m}^{2}, 7.40 \mathrm{~kJ} / \mathrm{m}^{2}$ and 6.67 $\mathrm{kJ} / \mathrm{m}^{2}$ which represents three separate outdoor occupations modeled i.e. drivers/commuters, construction workers and traders respectively while the dosimeters worn under clothe cover had the least values of $2.06 \mathrm{~kJ} / \mathrm{m}^{2}, 2.56 \mathrm{~kJ} / \mathrm{m}^{2}$, $3.07 \mathrm{~kJ} / \mathrm{m}^{2}$ at the market square, car park and construction site respectively. Overall, the cumulative exposures estimated for construction workers, maker women and traders and commuters in north bank car park were $3526.92,610.98$ and $1923.84 \mathrm{~kJ} / \mathrm{m}^{2}$ respectively. These values are quite high and we recommend that risky behaviors which would lead to both acute and chronic effects should be minimized.

\section{Acknowledgements}

The UV Polymer Polysulphone dosimeters used for this research were provided by Professor Alfio Parisi, from University of Southern Queensland, Toowoomba, Australia.

\section{References}

[1] Grandahl, K., Ibler, K. S., Laier, G. H., Mortensen, O. S. (2018) Skin cancer risk perception and sun protection behavior at work, at leisure, and on sun holidays: a survey for Danish outdoor and indoor workers, Environmental Health and Preventive Medicine, 23: 47, https://doi.org/10.1186/s12199-018-0736-x.

[2] Alberto M., Leena K. and Fabriziomaria G. (2018). Solar Radiation Exposure and Outdoor Work: An Underestimated Occupational Risk, International Journal of Environmental Research and Public Health. 2018, 15, 2063.

[3] Glanz, K., Buller, D. B., Saraiya, M. (2007) Reducing Ultraviolet exposure among outdoor workers: state of the evidence and recommendations, Environmental Health, 6: 22.

[4] Igbawua T., Ikyo B., Agba E. (2013). Average Solar UV Radiation Dosimetry in Central Nigeria, International Journal of Environmental Monitoring and Analysis. 1: 323-327. doi: 10.11648/j.ijema.20130106.18.

[5] Park, S. S., Lee, Y. G., Kim, M., Kim, J., Koo, J., Kim, C. K., Um, J., Yoon, J. (2019) Simulation of Threshold in UV exposure Time for vitamin D synthesis in South Korea, Advances in Meteorology, pages https://doi.org/10.1155/2019/4328151.

[6] Engelsen, O. (2010) The relationship between Ultraviolet radiation exposure and vitamin D status, nutrients 2 (5): 482495, https://dx.doi.org/10.3390\%2Fnu2050482.

[7] Grant, B. W. (2007) Roles of solar UV radiation and vitamin $\mathrm{D}$ in human health and how to obtain vitamin D, Expert Rev. Dermatol, 2: 563-577, doi: 10.1586/17469872.2.5.563.

[8] Diffey B. L. (1991). Solar ultraviolet radiation effects on biological systems. Phys Med Biol.; 36 (3): 2 99-328.

[9] Modenese A., Korpinen, L., Gobba, F. (2018) Solar radiation exposure and outdoor work: An underestimated occupational risk, International Journal of Research and Public Health, 15: 2063, doi: 10.3390/ijerph15102063.

[10] World Health Organization (WHO) (2016) Radiation: Ultraviolet (UV) Radiation. Retrieved from https://www.who.int/news-room/q-a-detail/radiationultraviolet-(uv) on $22^{\text {nd }}$ April, 2021

[11] US Food and Drug Administration (FDA) (2020) Ultraviolet (UV) radiation, Retrieved from https://www.fda.gov/radiation-emittingproducts/tanning/ultraviolet-uv-radiation on $21^{\text {th }}$ April, 2021.

[12] Parisi, A. and Turnbull, D. J. (2006) Solar UV dosimetry. In: UV Radiation and its Effects: an Update 2006, 19-21 Apr 2006, Dunedin, New Zealand.

[13] Parisi A. V., Turnbull D. J., Schouten P., Downs N., Turner J. (2010) Techniques for Solar Dosimetry in Different Environments. In: Gao W., Slusser J. R., Schmoldt D. L. (eds) UV Radiation in Global Climate Change. Springer, Berlin, Heidelberg. https://doi.org/10.1007/978-3-642-03313-1_7.

[14] International Commission on Non-Ionizing Radiation Protection (ICNIRP) (2007). Protecting Workers from Ultraviolet Radiation (ISBN 978-3-934994-07-2) retrieved from https://www.who.int/uv/publications/Protecting_Workers_UV_ pub.pdf on $22^{\text {nd }}$ April, 2021. 
[15] Sabburg J, Alfio V. Parisi, Wong J., (2001) Effect of Cloud on UVA and Exposure to Humans. Photochemistry and Photobiology 74 (3): 412-6.

[16] Thieden, E., Agren, M. S., Wulf, H. C. (2000) The wrist is a reliable body site for personal dosimetry of ultraviolet radiation, Photodermatol Photoimmunol Photomed 16: 57-61.
[17] Herlihy E., Gies P. H., Roy C. R. and Jones M. (1994) Personal Dosimetry of Solar UV Radiation for Different Outdoor Activities. Photochemistry and Photobiology 60 (3): 288-294. 